\title{
Energy conservation at high power consuming holding furnace with modified coil design and electrical circuits
}

\author{
D. Karthikeyan, V. P. Arumbu, P. Divya, K. Vijayakumar, K. Mani Rahulan \\ SRM Institute of Science and Technology, Kattankulathur, Chennai, India
}

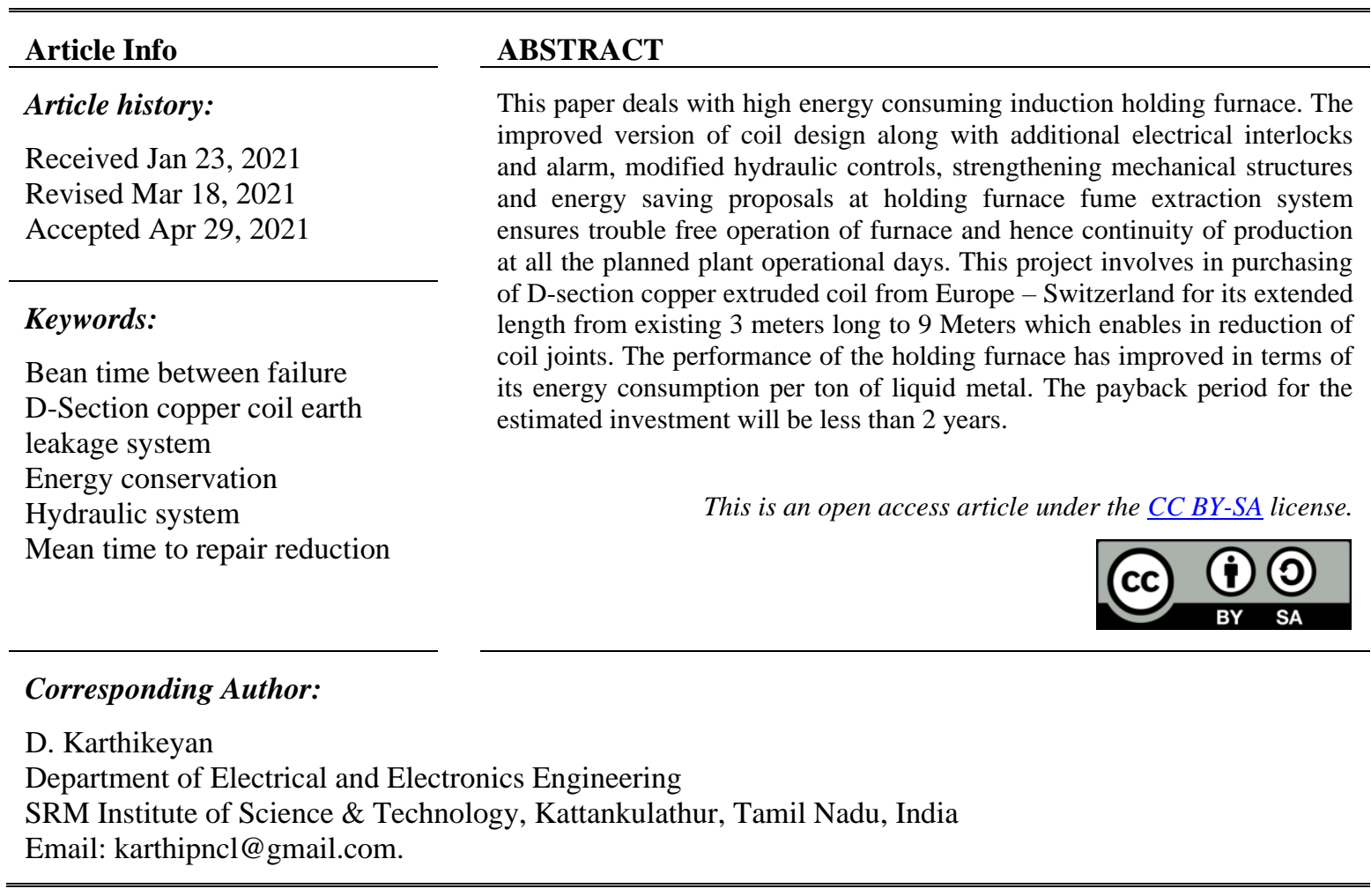

\section{INTRODUCTION}

Among the industries, casting manufacturing foundry industry consumes more electrical energy to melt the raw material in to liquid form to pour in the desired moulds made as per the requirement. The melting process consists of melting furnace, holding furnace and pouring furnace. Each stage consumes its specific energy based on its type and capacity. We at M/s. Brakes India Ltd., foundry division, and sholinghur operates Induction type coreless furnaces for this melting and holding of metal [1]-[4]. The average power consumption per ton of metal at melting furnace is 540 units and for holding furnace is 40 units/ton of liquid metal.

Foundry process is a continuous process, all the machines are operated in sequence to complete the process of metal pouring in to moulds. Any minor stoppage at line causes huge energy loss. The energy spent towards preparing the metal, moulds, operating dust collector equipment's and the process equipment's were all in vain. Hence, it is advantage when the machines operate at lesser breakdown occurrences and duration. This project of reducing the energy consumption at holding furnace by identifying the root cause of failures and implementing the improvements in the phased manner [5].

Figure 1, repesents the principle of electromagnetic induction utilizes the magnetic effect of the electrical current. When two conductors are magnetically coupled, and if the first conductor is carrying the A.C electrical current a secondary current is induced in a second conductor. This induced secondary current can be utilized to generate heat in the circuit of the second conductor by exploiting the electrical losses due to the current. In conventional method of heating, there is a hot source and a cold receiver. The source is going on expanding energy irrespective of whether the receiver receives it or not. While in induction heating, there is no hot source. Heat is induced inside the metal itself by the electromagnetic induction. And hence, energy 
is expanded only when metal receives it [6]. The hottest thing is the metal itself. So, the losses of hot sources are totally eliminated. Since the energy is not transferred by conventional method of heat transfer by conduction, convection or radiation. But it is generated (induced) in the metal itself. It is most efficient and clean method of heating the metal. Since the heat is generated within the metal itself, the amount of energy transfer per given mass of metal (power density) can be increased and heating process could be made quicker. And as the process becomes quicker, the process of efficiency improves.

To generate quick heat in the metal, we need to generate higher electrical losses in the metal to be melted or heated. The heating is directly related with the frequency of the electrically induced current. And so, to generate more heat (electrical losses), the higher frequency should be generated by designing proper inverter circuits. Even though the higher frequency of induced current is better for faster heating, there are other effects of this frequency which sometimes restricts the frequency rise. These effects are, liquid metal stirring in case of melting, depth of penetration of heat in case of heating or welding [7].

These other effects of frequency are also of great help to make the liquid metal stir and mix properly in melting and to control the depth of hardening or depth of welding in heating and welding. So, the frequency of the inverter is to be selected considering all these effects of it. The phenomenon of electrical induction is the induction of the secondary current in to the piece of the metal to be heated or melted or to be welded. To induce (generate) current in to the piece, it has to be placed in to the centre of the coil of conductor, which is carrying the electrical current of selected frequency. Thus, this piece forms the secondary connection between electrical supply and piece. However, there is the magnetic coupling between coil and the piece [8].

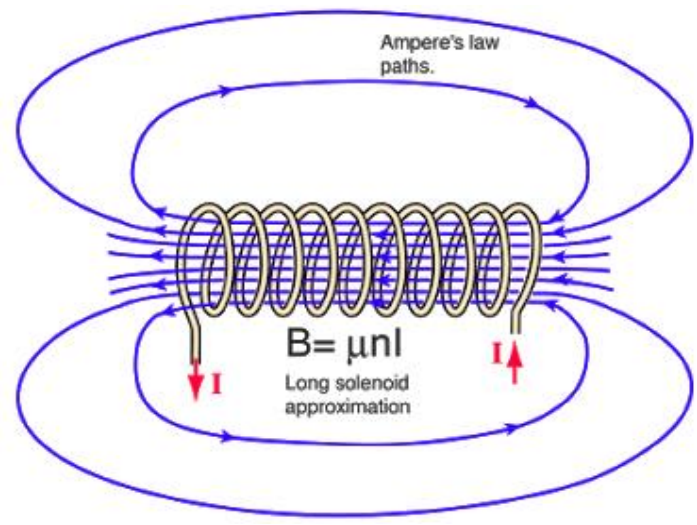

Figure 1. Magnetic field creation in the coil by the induced current

The stirring of the liquid metal is of vital importance for better alloying of the ingredients of the liquid metal. The stirring also helps to remove the entrapped air and float the slag on the top of the liquid metal [9], a) induction coil (coil of the conductor), b) electrical current passing through the induction coil, c) shunts around the periphery of the coil, d) monolithic refractory lining between induction coil and the metal, and e) metal.

The 22 Ton capacity holding furnace is fabricated using $45 \times 32 \mathrm{~mm} \mathrm{D}$ section extruded copper wounded coil. The total coil is made using 9 segments of coil turns. Each segment is made up of 4 to 5 turns. The extruded 3 meter coil is jointed using suitable ferrule joints is wounded on a drum to bring the required round shape. This total 43 turn coil is connected across $1200 \mathrm{~V}, 600 \mathrm{kw}$ Power transformer. The total number of joints to make this coil is around 80 Nos. This total coil is placed in a steel shell arrangement and locked with required arrangements to avoid dislocations. 8 nos of copper shunts placed all around the circumference of coil to nullify the leakage fluxes creating at coil. These shunts helps in eliminating leakage fluxes and also gives required mechanical support to the electrical coil from expansion and contraction due to heating and cooling process. A closed loop cooling system will take care of the coil from overheating. Monitoring, alarm, power trip controls were incorporated to the coil to avoid any damage due to heat. This internal cooling is maintained with in the limit using secondary cooling tower and heat exchanger setup these secondary cooling also maintained with in the limit by periodical cleaning of tank, cooling fills and heat exchangers. This coil is supplied through $3 \mathrm{ph}, 11 \mathrm{kv} / 1200 \mathrm{~V}$, and $600 \mathrm{kw}$ transformer. A phase balancing panel consists of series connected inductor and capacitor banks connected through contactors are balancing the 3ph current [10]. 
The reasons associated to this is,are as follows first one is water leak due to copper coil joint failure $\&$ high temperature at primary and secondary cooling waters, next to it is lifting and lowering problems due to hydraulic circuits \& earth leak detections due to high temperature at cooling jackets, followed with PLC hardware failures, incompetent in trouble shootings, heat loss due to fume extractor operation, field failures of electrical components with more time taken to correct the failures, and the alarm and feedback facilities are not user friendly.

In addition with the above constraints the following problems are added towards the maintance and electrical power consumptions they are briefly given as following the first one is more energy consumption / ton of liquid metal. Secondly the present level of energy/ton of liquid metal is 40 Unit More number of plant stoppages due to break downs at holding furnace. Number of break downs, at year wise are 2016-1:5 occurrences, 2017-18:5 occurrences, and 2018-19:1 occurrence the third problem is related to the repair and maintenance cost is high, at 2016-17:15 Lakhs, 2017-18:10 Lakhs, and 2018-19:1.5 Lakhs lastly its deals with the production shutdown in the range of Less productivity during the failure days. Loss of 10 Tons of metal pouring / hr break down.

\section{OBJECTIVES}

The following derived objectives gives the soloution for the above mentioned problems which are labeld here as follows first and foremost is to incorporate electrical controls to raise alarm before failures that causes energy losses, Modifying furnace coil design to avoid joint failures \& incorporating additional controls on hydraulic circuits.finally to Improve the condition of instrumentation panel with cooling arrangement, Strengthening the mechanical structures and at last implementing energy saving proposals at fume extraction system.

\subsection{Operation of 22 Ton capacity holding furnace}

\subsubsection{Existing model introduction}

Figure 2 reperents the $22 \mathrm{~T}$ capacity holding furnace consists of power and instrumentation panel. The furnace receives power from phase balancing power. The furnace is of core less type induction furnace operating at main's frequency [11]-[14].

It does not possess any semiconductor devices. It has got combination of series reactors and shunt capacitors to balance the three-phase current. Cooling system to the coil is by demin water with the conductivity of less then 100 micro siemens. We got two such furnaces. One will operate at a time and the next one will be stand by. It will operate around 50 day's cycle [15]-[17].

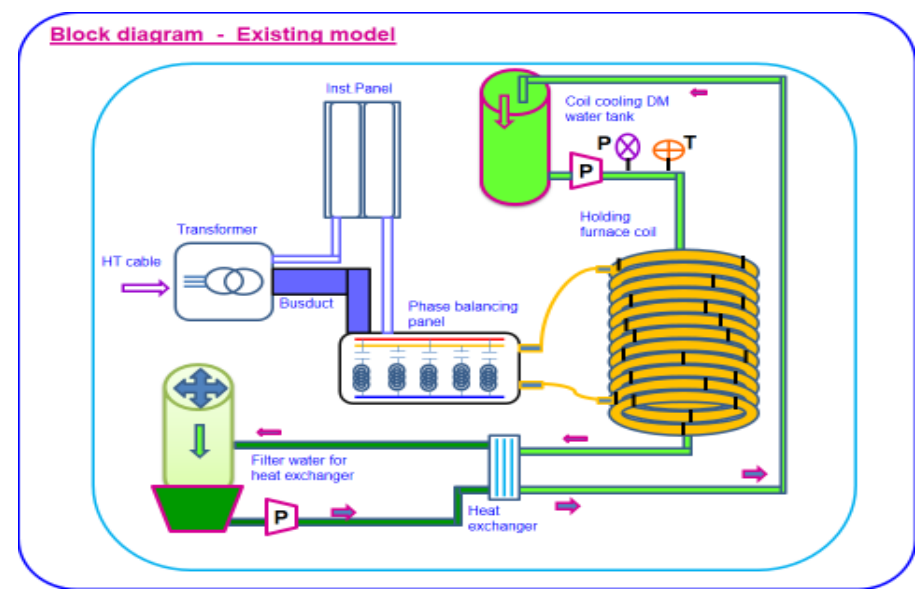

Figure 2. Block diagram of the existing model

\subsubsection{Comparison between exixting and propsed block diagram}

Figure 3 represents the block diagram of the proposed model with the comparison of need changes discovered between the existing and the proposed model which clearly shown the major diffrence in the coil design with respect to the exixting one, the propsed model deals with the new coil design with addition coupling placed at the right location which reduce the major problem like high power consumption and high maintance cost, in addition the key points of difference between the block digrams are addressed for clear 
understanding towards the improved model in Table 1 [18]-[20]. Table 2 represents the break down details happens in the industries from the period of Apr 2016-Mar 2019 and the loction of the failure happens has been repesentedin the Figure 4.

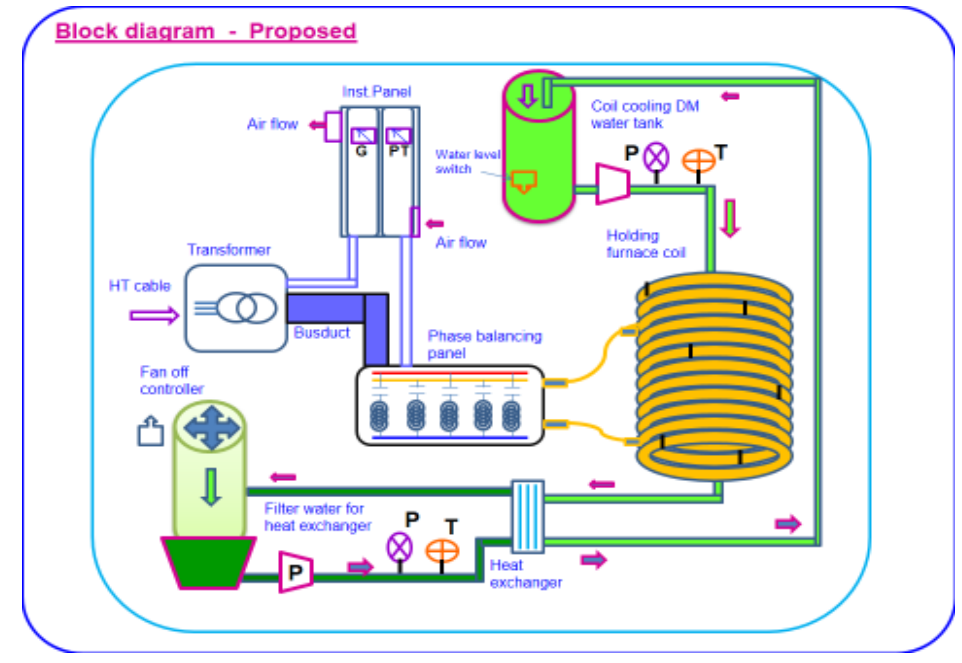

Figure 3. Block diagram of the proposed model

Table 1. Comparison with existing and proposed model block diagram

\begin{tabular}{|c|c|c|}
\hline No. & Block diagram - Existing & Dlog diagram - Proposed \\
\hline 1. & Number of coil joints are more - around 80 joints & $\begin{array}{l}\text { Number of coil joints are reduced to } 22 \text { joints which avoid } \\
\text { failure rate of coil joints and water leak issues }\end{array}$ \\
\hline 2. & No water level controller at DM water tank & Water level controller at DM water tank introduced \\
\hline 3. & No pressure sensor at filter water line & $\begin{array}{l}\text { Pressure sensor at filter water line to raise alarm to avoid } \\
\text { break down }\end{array}$ \\
\hline 4. & No temperature sensor at filter water line & $\begin{array}{l}\text { Temperature sensor at filter water line to raise alarm to avoid } \\
\text { break down }\end{array}$ \\
\hline 5. & $\begin{array}{l}\text { Total coil is connected across the supply - more hear } \\
\text { generation at metar parts }\end{array}$ & $\begin{array}{l}\text { Dummy coil is provided at top and bottom to avoid heating of } \\
\text { metal parts and eath leak issues }\end{array}$ \\
\hline 6. & No ground leak detector check methods & Testing facilities created to check the ground leak detection \\
\hline 7. & $\begin{array}{l}\text { No alert alarm for cooling tower fan operation - will } \\
\text { lead to high temperature issues }\end{array}$ & $\begin{array}{l}\text { Gemerate alarm for cooling tower fan off status - will } \\
\text { eliminate cooling water high temperature issues }\end{array}$ \\
\hline 8. & More PLC hardware failure & Cooling fan with filters provided \\
\hline 9. & $\begin{array}{l}\text { No power tap position controller to control wastage of } \\
\text { power }\end{array}$ & Powe tap position controller to save energy. \\
\hline
\end{tabular}

Table 2. Break down details from Apr 2016-Mar 2019

\begin{tabular}{|c|c|c|c|c|}
\hline 1 & Holding furnace-1 & 01.08 .2016 & $\begin{array}{l}\text { Holding furnace- } 1 \text { coil water leak } \\
\text { from bottom } 5 \text { th turn }\end{array}$ & $\begin{array}{l}\text { Immediately furnace emptied. Spare } \\
\text { holding furnace switched on and put } \\
\text { into operation. }\end{array}$ \\
\hline 2 & Holding furnace-2 & 03.08 .2016 & $\begin{array}{l}\text { Holding furnace- } 2 \text { water leak } \\
\text { from inlet turn port }\end{array}$ & $\begin{array}{l}\text { Immediately furnace emptied. Brazing } \\
\text { work carried out at coil inlet turn port } \\
\text { and put into operation. }\end{array}$ \\
\hline 3 & Holding furnace- 2 & 03.10 .2016 & $\begin{array}{l}\text { holder tilting cylinder oil leak due } \\
\text { to piston rod gland seal worn out }\end{array}$ & Spare tilting cylinder replaced. \\
\hline 4 & Holding furnace- 1 & 06.01 .2018 & $\begin{array}{l}\text { Holding furnace-1 lifting up/down } \\
\text { not working }\end{array}$ & $\begin{array}{l}\text { Holder up/down not working due to } \\
\text { Proportional card base terminal cut } \\
\text { Spare proportional card with base } \\
\text { replaced. }\end{array}$ \\
\hline 5 & Holding furnace- 1 & 19.03.2019 & $\begin{array}{l}\text { Holding furnace- } 1 \text { water leak at } \\
\text { bottom coil }\end{array}$ & $\begin{array}{l}\text { Water leak noticed at bottom coil } 7 \text { th } \\
\text { turn brazed area got crack. Same was } \\
\text { brazed with copper supports and } \\
\text { strengthened. }\end{array}$ \\
\hline 6 & Holding furnace- 2 & 27.03.2019 & $\begin{array}{l}\text { Holding furnace- } 2 \text { tilting } \\
\text { movement problem }\end{array}$ & $\begin{array}{l}\text { Pressure relief valve spool got struck. } \\
\text { Spare relief valve changed after that } \\
\text { production continued. }\end{array}$ \\
\hline
\end{tabular}




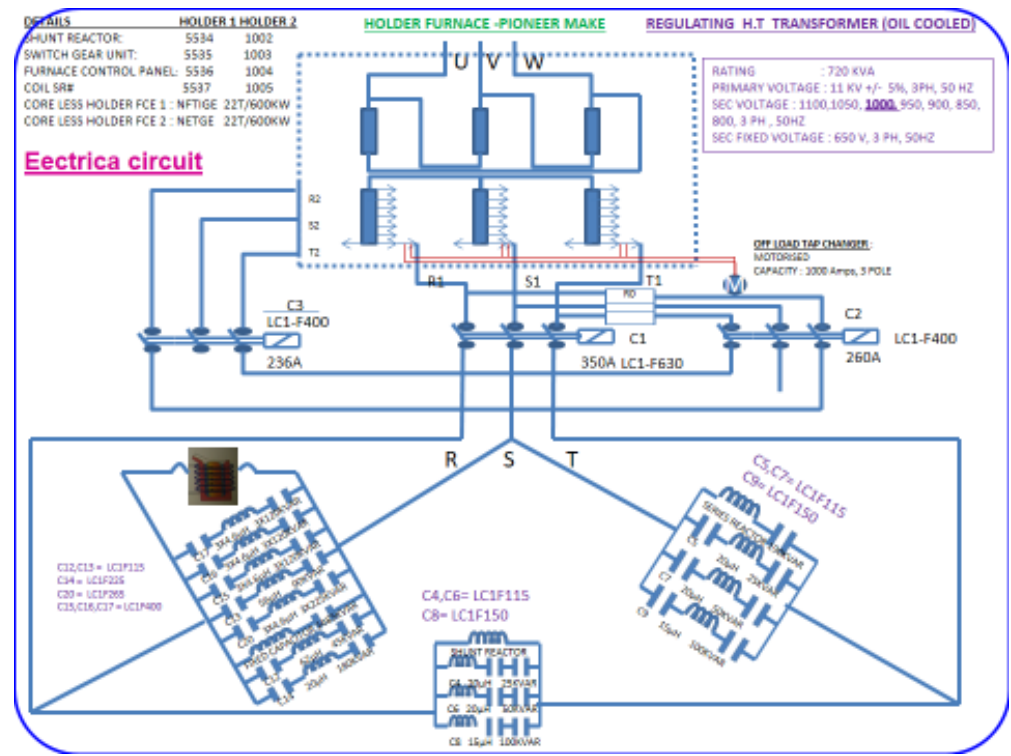

Figure 4. Failure holder furnace panel.

\subsection{Failure details}

The major drwabacks in the existing model are listed over here as follows as no power tap position controller to control wastage of power, Number of coil joints are more-around 80 joints, Total coil is connected across the supply-more hear generation at metal parts \& No alert alarm for cooling tower fan operation-will lead to high temperature issues and at the last no ground leak detector check methods with more PLC hardware failures.

\subsection{Coil related modifications}

To resolve the above mentioned problems step by step action taken has been incorporated in a the short time duration of gap improve the coil performance which are labelled as follows initially it has been Providing additional water cooling to the cooling jacket, Apr-Sep 2017 next to it replacing existing coil with better coil joint, Apr-Sep 2017 \& increasing the length of coil from 3 meters to 9 meters to reduce the number of coil joints, Apr-Sep 2017 with relocating the power feeding joint to avoid induction losses, AprSep 2017 \& Improving coil segment joints, Apr-Sep 2017.

\subsection{Hydraulic system modifications \& improvements at instrument panel}

Added with the coil design the hydraulic system modification and panel side development has been implemented in order to meet out the solution in the fullest way they are narrated as follows, firstly improving the cooling of hydraulic oil, Oct 17-March 18, Fixing replacement frequency of oil filter elements, Oct 17-March 18, incorporating oil level low sensor to alert and to reduce oil cost and the repair time, Oct 17-March 18 \& giving additional angle supports to avoid cracks, Oct 17-March 18, incorporating suction damper control for various stage operation and furnace \& providing cooling fan arrangement for instrument panel, Apr-Sep 2018, providing air circulation with necessary filter to avoid dust entry, Apr-Sep 2018 with proving water level sensor for primary water tank, Apr-Sep 2018 \& incorporating necessary fuse protection for individual field outputs for protection and easy trouble shootings, Oct 18-March 19 [21]-[25]. Increasing the capacitor at panel to improve power factor of the feeder, Oct 18-March 19 added with SOP for fume extraction operation to save electrical energy, Oct 18-March 19 \& displaying electrical schematic diagram for better understanding, Oct 18-March 19. Displaying the functional procedures of major systems like cooling, Hydraulic, power, Oct 18-March 19 with the identification of circuit components with description and circuit reference for easy trouble shooting, Apr-Sep 2018 \& Developing fault annunciation at HMI for easy trouble shooting, Apr-Sep 2018

After all the modification has been done is a huge reduction in breakdown occurrences at holding furnacere which is shown in graph at Figure 5 and the improvement in holder energy consumption is indicted in the graph at Figure 6. 


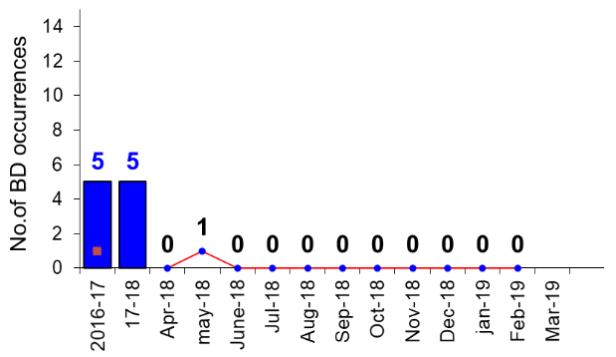

Figure 5. Reduction in breakdown occurrences at holding furnacere

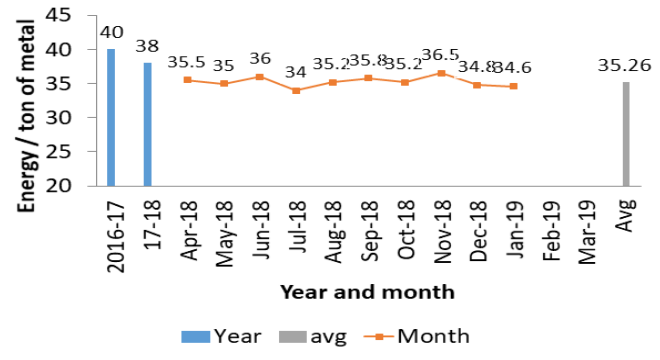

Figure 6. Improvement in holder energy consumption

\section{ENERGY SAVING CALCULATION TO ACHIVE IMPROVEMENT}

The evaluation of the improvement has been calculated as energy saving which has narrow down as following, firstly Total metal handled by this holding furnace for the year 2018-19, is 55000 Tons added with it the average energy consumption/ton of metal is 35.26 units \& Energy saving/ton of metal compared to last year, 2 units secondly the total energy saved for the year 2018-19 (11 months), 55000x2=110000 units in terms of cost: $1,10.000 x$ Rs, $7=7,70.000 /=$ for this year.

Note: We have not considered the benefit of production by this improvement

- Investment cost for the above improvements

The following suggestions are identified as a part of improvement related to the financial aspect in the industry which are given as ,The major cost involved is in the coil joint modification $\&$ the original length of 3 meter with 80 Joint is replaced by 9 meter long and 22 joints, Secondly the cost incurred for the above coil modification is Rs, 12.0 Lakhs/coil thirdly the cost incurred for the other improvements is Rs, 3.0 Lakhs, at last the huge savings in the total investment is Rs, 15.0 Lakhs with the Payback period is 2 years

Note: we have not considered the benefit of production by this improvement.

\section{HARDWARE PHOTOS OF IMPROVEMENT}

Figure 7-10 represents the true industrial pictures of improvement ideas implants with respect to coil design and its overall control aspects. The first figure 7 represents the changes made in the coil design i.e. the number of joint has been reduced added to it the figure 8 denotes its physical industrial representation in order to monitor the temperature level of the coil the temperature control set value has been fixed in the new design the whole design has been controlled automatically using scada control panel.

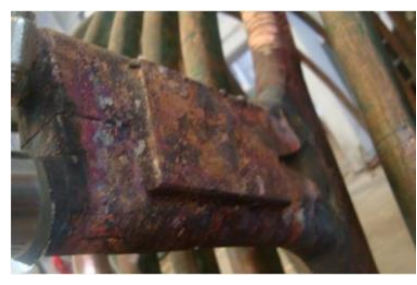

Figure 7. Implemetaion of coil design in the industries

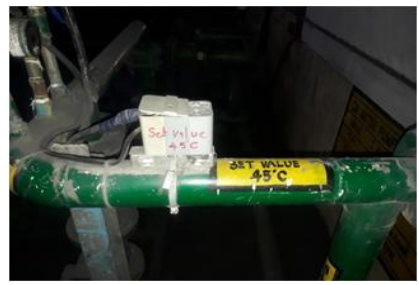

Figure 9. Coil temperature set value

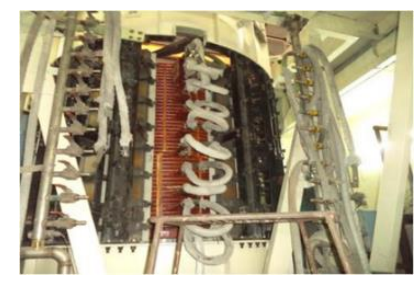

Figure 8. overall view of improved coil design in the industries

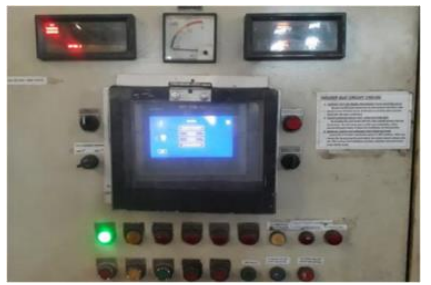

Figure 10. Control panel for coil temperature control 


\section{CONCLUSION}

By implementing the identified improvements at holding furnace, we are saving around 1 Lakh electrical units/year apart from benefits of production advantages. The main reason for increase of electrical energy consumption/ton of liquid metal handling is the machine break downs due to electrical controls failures, hydraulic control failures, and water leak from induction coil joints, structural damages, and PLC hardware components failure. The identified improvements against the failures are to incorporate electrical controls to minimize energy losses, external water pressure and temperature sensors and by providing additional water cooling to the cooling jacket, \& fixing water level sensor for primary water tank, and providing additional controls for detecting earth leakage. Modifying furnace coil design to avoid joint failures, by replacing existing coil with better coil joint, increasing the length of coil from 3 meters to 9 meters to reduce the number of coil joints, relocating the power feeding joint to avoid induction losses, and improving coil segment joints.

\section{ACKNOWLEDGEMENTS}

I would like to thank my co authors and my industrial friends, who had extended their valuable support to my research work.

\section{REFERENCES:}

[1] M. E. El-Hawary, Principle of electric machines with power electronic applications, 2nd Edition, June 2002.

[2] Paul C. Krause, Oleg Wasynczuk and Scott D. Sudhoff, Analysis of electric machinery and drive systems, 2nd Edition.

[3] Narayan S. Rau, Optimization principles practical applications to the operation of marketsof the electric power industry, 2003.

[4] Vedam Subramanian, Power electronics, New Age International (P) Ltd 1996, Reprint at 2000.

[5] P. C. Sen, Principle of electrical machines \& power electronics, 2nd Edition, 2013.

[6] M. L. Soni, and P.V., Gupta power system engineering, Edition 2001.

[7] "IEEE Standard 141-1993: Recommended practice for power distributions to industrial plants," IEEE, 1994, DOI: 10.1109/IEEESTD.1994.121642.

[8] "IEEE Standard 519-1992: Recommended practices and requirements for Harmonic control in electrical power systems," IEEE, 1993, DOI: 10.1109/IEEESTD.1993.114370.

[9] B. H. Han, I. K. Chun, S. C. Lee, and S. Y. Lee, "Multichannel magnetic stimulation system design considering mutual couplings among the stimulation coils," IEEE Trans. Biomed. Eng., vol. 51, no. 5, pp. 812-817, May 2004.

[10] V Thiyagarajan, Micro electro mechanical systems, Anna University, Chennai, India, 2013.

[11] C. Ravichandran, Power electronics for renewable energy systems, Anna University, Chennai, India, 2013.

[12] P. L. Somasundaram, Electrical machines, Anna University, India, 2016.

[13] Tara Goldsworthy et al. HIsmelt-Ironmaking Technology in the Future[C]//China Iron and Steel Annual Meeting Proceedings. Beijing: Metallurgy industry press, 2003: 604-610.

[14] Wu Xian, Zhang Jian. Distribution and Characteristic of China's Titanium Resource [J]. Titanium Industry Progress, 2006, 23(6): 8- 12.

[15] Chen, Weitong, Chunhua Liu, Christopher Lee, and Zhiqiang Shan, "Cost effectiveness comparison of coupler designs of wireless power transfer for electric vehicle dynamic charging," Energies, vol. 9, no. 11, pp. 906, 2016, DOI: 10.3390/en9110906.

[16] S. Cui, Z. Z. Liu, Y. J. Hou, H. Zeng, Z. K. Yue and L. H. Liang, "Study on efficiency of different topologies of magnetic coupled resonant wireless charging system," IOP Conference Series Earth and Environmental Science, vol. 93, no. 1, pp. 012064, 2017, DOI: 10.1088/1755-1315/93/1/012064.

[17] Tianqing Li, Xiangzhou Wang, Shuhua Zheng, and Chunhua Liu, "An efficient topology for wireless power transfer over a wide range of loading conditions," Energies, vol. 11, no. 1, pp. 141, 2018, DOI: 10.3390/en11010141.

[18] Paolo Batezzato, Wireless battery charging, White-Paper, ST, Technology Tour, 2017.

[19] Du HeGui, et al. Principles of Smelting Vanadium-titanium Magnetite by Blast Furnace [M]. Beijing: Science Press, 1996.

[20] M. Saravanan, and A. Ramesh Babu, "High power density multi-mosfet-based series resonant inverter for induction heating applications," International Journal of Power Electronics and Drive System (IJPEDS), vol. 7, no. 1, March 2016, pp. 107-113, DOI: 10.11591/ijpeds.v7.i1.pp107-113.

[21] M. N. Tandjaoui, C. Benachaiba, O. abdelkhalek, B. Denai, and Y. Mouloudi, "Characterisation and modelling of power electronics device," International Journal of Power Electronics and Drive System (IJPEDS), vol. 5, no. 2, October 2014, pp. 135-14, DOI: 10.11591/ijpeds.v5i2.4318.

[22] Hussain Attia, and Ali Sagafinia, "Novel discrete components based speed controller for induction motor," International Journal of Power Electronics and Drive System (IJPEDS), vol. 7, no. 4, December 2016, pp. 10751084, DOI: 10.11591/ijpeds.v7.i4.pp1075-1084. 
[23] A. Ali, M. N. M. Yasin, M. F. C. Husin, N. A. M. Ahmad Hamb Ali, "Design and analysis of 2-coil wireless power transfer (WPT) using magnetic coupling technique," International Journal of Power Electronics and Drive System (IJPEDS), vol. 10, no. 2, pp. 611-616, June 2019, DOI: 10.11591/ijpeds.v10.i2.pp611-616.

[24] Masood Rehman, Perumal Nallagownden, and Zuhairi Baharudin, "Efficiency investigation of SS and SP compensation topologies for wireless power transfer," International Journal of Power Electronics and Drive System (IJPEDS), vol. 10, no. 4, pp. 2157-2164, December 2019, DOI: 10.11591/ijpeds.v10.i4.pp2157-2164.

[25] G. Balamurugan, S. Punniakodi, K. Rajeswari, and V. Arulalan, "Automatic number plate recognition system using super-resolution technique," 2015 International Conference on Computing and Communications Technologies (ICCCT), pp. 273-277, 2015.

\section{BIOGRAPHIES OF AUTHORS}
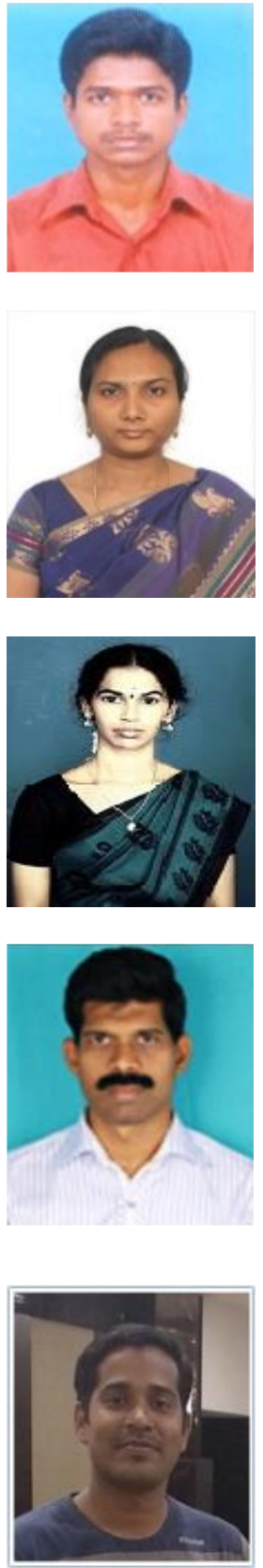

D. Karthikeyan was awarded a B.E. Degree from the Electrical and Electronic Engineering Department of A.I.H.T College, Chennai, India (affiliated to Anna University, Chennai, India), in 2009; and M.Tech. Graduated from SRMIST (formerly SRM University), Kattankulathur, India, in Power Electronics and Drives in 2013, he completed his Ph.D. in Multilevel Inverters in 2019. He currently works as an Assistant professor at SRMIST (formerly SRM University) in the Department of Electrical Engineering, Kattankulathur, and Chennai, India. His current research interests include power electronic multilevel inverters, AC drives, and DC drives. He is a member of various professional societies such as the IEEE, IET, IEI and ISCA.

Arumbu V $\mathbf{P}$ received her B.E. degree from the Department of Electrical and Electronics Engineering from Kalasalingam College of Engineering and Technology, Chennai, India (affiliated with Anna University, Chennai, India), in 2005; and her M.Tech. degree in Power Electronics and Drives from SRMIST (Formerly SRM University), Kattankulathur, India, in 2013, Now she is doing her Ph.D. degree in SRMIST . She was previously working with thiru seven hills polytechnic as a lecturer in EEE dept, prior to that she was working at SA polytechnic Chennai, India. Her current research interests include Power Electronics, Multilevel Inverters.

P Divya received her B.Sc \& M.Sc physics in E.G.S.Pillay Arts \& Science College, Nagapattinam tamilnadu, india (Affliated to Bharathidasan university trichy) in the year 2011 \& 2012 respectively she had completed her M.Phil physics in T.B.M.L.College, Porayar, Nagapattinam. (Affliated to Bharathidasan university trichy) now she is doing her Ph.D in SRMIST.Her area of research interests are Nano particle synthesis \& Non linear optics.

Vijayakumar Krishnasamy received his B.E. and M.E. degrees from Annamalai University, Annamalai Nagar, India; and his Ph.D. degree from SRMIST (Formerly SRM University), Kattankulathur, India. He is presently working as a Professor and as the Head of the Department of Electrical and Electronics Engineering of SRMIST (Formerly SRM University). His current research interests include power system modeling, power electronics converters for gridconnected PV systems, computational intelligence applications in power systems, FACTS devices, and power quality. He has been awarded the Best Teacher Award in his department for the academic years 2004 and 2006. He is a member of various professional societies such as the IEEE, IET, FIE, ISTE, and ISCA.

K Mani Rahulan received his M.Sc \& Ph.D (material science) at Anna university guindy Chennai tamilnadu india, in the year 2006 \& 2013 respectively. He currently works as an Assistant professor at SRMIST (formerly SRM University) in the department of physics and nanotechnology.his current research interest includes Nano particle synthesis \& Non linear optics. 